\title{
Erratum: Romero-Lopez et al. Lung Metabolomics Profiling of Congenital Diaphragmatic Hernia in Fetal Rats. Metabolites 2021, 11, 177
}

\author{
Maria del Mar Romero-Lopez ${ }^{1,2} \mathbb{D}^{\mathbb{D}}$, Marc Oria ${ }^{1,3}{ }^{\mathbb{D}}$, Miki Watanabe-Chailland ${ }^{4}$, Maria Florencia Varela ${ }^{1}(\mathbb{D}$, \\ Lindsey Romick-Rosendale ${ }^{4}$ and Jose L. Peiro ${ }^{1,3, *}$
}

check for updates

Citation: Romero-Lopez, M.M.; Oria, M.; Watanabe-Chailland, M.; Varela, M.F.; Romick-Rosendale, L.; Peiro, J.L. Erratum: Romero-Lopez et al. Lung Metabolomics Profiling of Congenital Diaphragmatic Hernia in Fetal Rats Metabolites 2021, 11, 177. Metabolites 2021, 11, 229. https://doi.org/ 10.3390/metabo11040229

Received: 6 April 2021

Accepted: 7 April 2021

Published: 9 April 2021

Publisher's Note: MDPI stays neutral with regard to jurisdictional claims in published maps and institutional affiliations.

Copyright: (C) 2021 by the authors Licensee MDPI, Basel, Switzerland. This article is an open access article distributed under the terms and conditions of the Creative Commons Attribution (CC BY) license (https:// creativecommons.org/licenses/by/ $4.0 /)$
1 Center for Fetal and Placental Research, Division of Pediatric General and Thoracic Surgery, Cincinnati Chidren's Hospital Medical Center (CCHMC), Cincinnati, OH 45229, USA; maria.romero.lopez@cchmc.org (M.d.M.R.-L.); marc.oria@cchmc.org (M.O.); maria.florencia.varela@cchmc.org (M.F.V.)

2 Perinatal Institute, Division of Neonatology, Cincinnati Children's Hospital Medical Center, Cincinnati, $\mathrm{OH} 45229$, USA

3 Department of Surgery, College of Medicine, University of Cincinnati, Cincinnati, OH 45267, USA

4 NMR-Based Metabolomics Core, Division of Pathology and Laboratory Medicine, Cincinnati Children's Hospital Medical Center, Cincinnati, OH 45229, USA; Miki.Watanabe@cchmc.org (M.W.-C.); Lindsey.romick-rosendale@cchmc.org (L.R.-R.)

* Correspondence: jose.peiro@cchmc.org; Tel.: +1-(513)-636-3494

The authors wish to make the following corrections to this paper [1].

On page 11, in the original manuscript, Figure 6 was a repeat of Figure 5 by mistake. The following is the correct Figure 6:

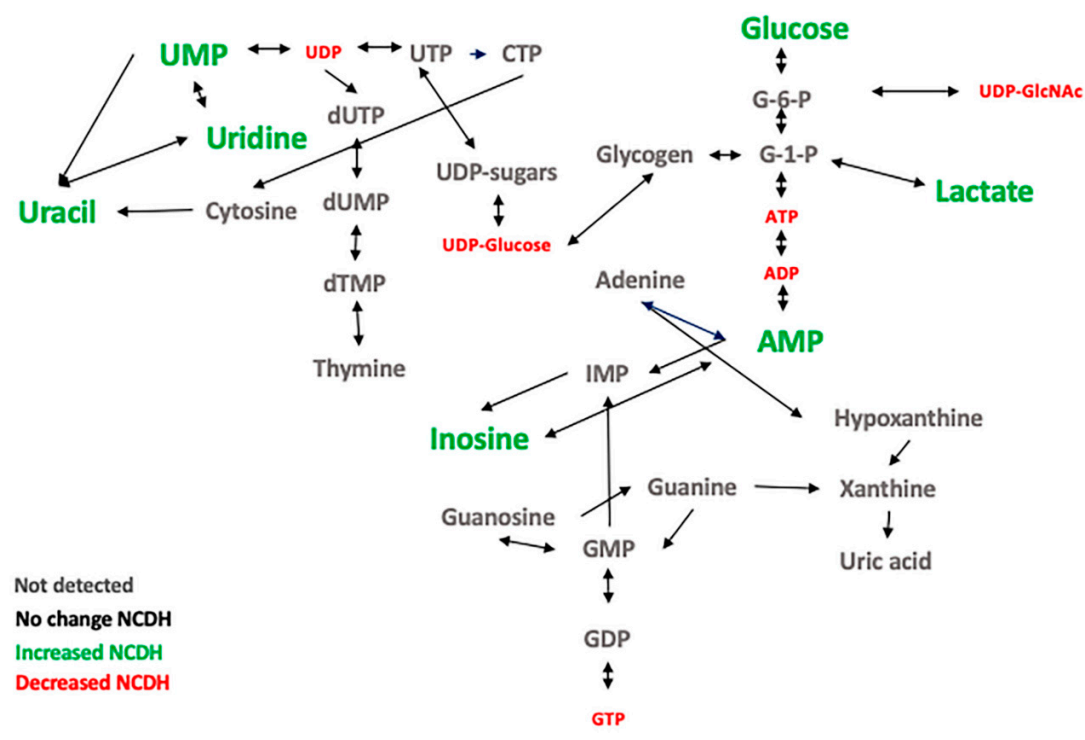

Figure 6. Alterations of nucleotide metabolism in fetal $\mathrm{CDH}$ lung. The overview of the metabolic flow of nucleotide metabolites and changes identified in the NCDH group compared with the VC group. Green (increased), red (decreased), black (no change), and grey (undetected).

Conflicts of Interest: The authors declare no conflict of interest.

\section{Reference}

1. Romero-Lopez, M.M.; Oria, M.; Watanabe-Chailland, M.; Varela, M.F.; Romick-Rosendale, L.; Peiro, J.L. Lung Metabolomics Profiling of Congenital Diaphragmatic Hernia in Fetal Rats. Metabolites 2021, 11, 177. [CrossRef] [PubMed] 